and to anterior superior spine of leftilium, $8 \mathrm{in.}$ On vaginal examination a soft rounded swelling was detected to the right of the uterus. The uterus was normal in length, the fundus pushed over slightly to the left.

The temperature taken in the rectum on several successive days was as follows :-

\begin{tabular}{|c|c|c|c|c|c|c|c|}
\hline & & orning. & Evening. & & & $n g$. & \\
\hline ax & & . $\quad \overline{99 \cdot 0^{\circ}} \ldots$ & $\begin{array}{l}100 \cdot \\
100\end{array}$ & Jan. & $\begin{array}{l}26 \text { th } \\
27 \text { th }\end{array}$ & $2^{\circ}$. & $0^{\circ}$ \\
\hline & & $99 \cdot 8 \ldots$ & . - & & 28 & & \\
\hline & & $100 \cdot 6$ & . $101^{\circ}$ & , & & & $100 \cdot 8$ \\
\hline & & 10 & & & 3 & & \\
\hline & & & & Feb. & & . 1 & 100 \\
\hline & & & & ", & & & \\
\hline & & & & צ" & & & \\
\hline & & & & 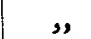 & & & 0 \\
\hline & & & 100 & & & 99.2 & \\
\hline
\end{tabular}

Jan. 27th.-Thirty-five ounces of pus, greenish-yellow in colour and without odour, were withdrawn by means of the aspirator through a puncture in the abdominal wall.

Feb. 2nd.-Vomiting continues, and the abdomen is resuming the aspect and dimensions it had before aspiration.

5th. - Emaciation progressing very rapidly. It was therefore decided to-day that an exploratory incision should be proposed to her, with a view to the removal, if feasible, of what was believed to be a suppurating cyst, probably ovarian. The risk was fairly set before her, and she urgently desired to have the chance which such an operation might afford her.

7th.-Accordingly, bichloride of methylene having been administered, an incision three inches in length was made in the median line, commencing above at a point an inch below the umbilicus. The abdominal muscles were carefully divided, and before the peritoneum was recognised, the pus-containing cavity was laid open, and a large quantity of fetid pus set free. On introducing the hand the cavity was found to correspond in extent with the area of dulness. No sac or pedicle was discoverable. When the pus had escaped, the posterior wall of the cavity presented the appearance of a slightly convex, thick mass of tissue, with a shreddy, uneven surface, on which there were abrasions or superficial ulcers here and there. The anterior and posterior walls of the cavity (which subsequently proved to be separated layers of the abdominal parietes) were firmly united on the right and on the left, and also superiorly, except at the right corner, where there was an opening large enough to admit a finger. Through this opening the lower edge of the liver could be distinctly touched. Inferiorly the surfaces were closely united on the left side of the median line, while on the right they were easily separated to a sufficient extent to allow a digital exploration of the pelvis. A little pus continued to well up from a small opening to the right of the median line in the lower border of the cavity. After separating the slightly adherent surfaces to the outer side of this opening, two fingers could readily be hooked round the lower border of the thick posterior wall of the cavity. The fingers being then directed downwards, the posterior wall of the uterus was felt; and to the right of the uterus, in immediate contact with it, a soft irregular mass was discovered, the interior of which was the spot from which the pus was oozing into the large cavity already described. Douglas's space was quite free. It was impossible to determine the exact condition of the parts, and the exploration was not pursued further. The walls of the cavity having been sponged with a lotion of carbolic acid, a drainage-tube was passed through the external incision, and brought out through the vagina behind the uterus. The wound was then closed with sutures. 'The vomiting continued, and the patient died at 6.15 P.Mr. on the same day.

Autopsy, eighteen hours after death.-Rigor mortis well marked. Incision, nnited by sutures, in median line of abdomen, three inches in length, opening into a large cavity. On reflecting the abdominal walls, this cavity was found to be due to a separation of the peritoneal and muscular layers of the abdominal parietes. It contained a small quantity of pus, and extended upwards from the pubes to a line on $a$ level with the lower margin of the eleventh rib. Laterally it was bounded by a line passing vertically upwards on each side from the anterior superior spinous process of the ilium. At the right superior angle of the cavity there was an opening large enough to admit the finger, which communicated with a transverse channel, bounded in front by the lower border of the liver, behind by the stomach, and below by the transverse colon. The transverse colon was adherent to the stomach and to the parietal peritoneum in such a manner that no communication existed between this transverse channel and the general peritoneal cavity. Pus was found in the channel, having made its way from the larger cavity through the opening described above. At the lower margin of the large intra-parietal cavity there was an opening two inches long immediately to the right of the median line, running upwards and outwards, parallel with Poupart's ligament. Through this opening the drainagetube was passed at the time of the exploratory operation, and at its inner angle was the spot where the suppurating right ovary had burst, discharging its contents between the layers of the abdominal wall. The right ovary was a mere sac, about equal in size to a hen's egg, containing purulent fluid. The left ovary, also enlarged, though to a much smaller extent, bad become converted into a small bag of purulent fluid. The wall of the left uvary was entire. The posterior wall of the intra-parietal cavity consisted not only of thickened peritoneum, but of omentum and several coils of small intestine, which had become firmly united to it; these structures, strongly matted together, formed the thick convex mass which proved so puzzling on the operatingtable. On dividing and turning aside this posterior wall, it was seen that the peritonitis had been limited to the anterior parietal peritoneum and the tissues immediately contiguous. The coils of intestine lying in the peritoneal cavity were free from any trace of inflammation. The uterus was thickened antero-posteriorly, owing to the presence in its anterior wall of three small fibroids, the largest of which was equal in size to a pigeon's egg. The liver was adherent throughout to diaphragm, stomach, and abdominal parietes. The kidneys and spleen healthy. The rioht lung was slightly adherent to the diaphragm, especially at its anterior inferior margin. The lower lobes of both lungs were congested posteriorly. The tissue of the heart was pale and flabby; the right ventricle was covered with a layer of fat, its walls were extremely thin and soft, and it contained a decolorised clot. The valves and orifices of the heart were normal.

\section{GENERAL HOSPITAL, MADRAS.}

FIBROUS TUMOUR OF BASE OF SKULL; REMOVAL; DEATH. (Under the care of Prof. J. L. RATron.)

THE following case, the notes of which were taken by Mrs. Scharlieb, clinical clerk, is chiefly interesting from the method adopted for plugging the pharynx. Professor Ratton says that he derived the idea from Dr. Trendelen. berg's trachea tampon, but he thinks that plugging has some advantages over the tampon. Three soft sponges about the size of small oranges, with strong tapes attached, were used for plugging the pharynx. Once plugged, not only were the food and air passages shut off from the operation, but there was practically a closed cavity, which could be readily filled with compresses in case of bæmorrhage.

Moonesawmy, a delicate anæmic lad, aged eighteen, who was admitted in to the surgical ward on the 19th May, 1877, had a tumour, which protruded from the left nostril and from beneath the upper lip. 'The tumour was of one year's growth, and first appeared in the left nostril. Owing to the expansion of the nasal bones and the widening of the upper juw, the appearance of a "frog's face" was well marked. The smaller portion of the tumour, the size of a pigeon's egg, and somewhat rounded, projected from the left nostril. The larger portion, irregularly lobulated, and about the size of a swan's egg, protruded between the alveolar process of the upper jaw and the upper lip. Both pcrtions were covered by mucous membrane, altered by exposure, and marked with superficial patches of ulceration. The nasal boves were raised to nearly a right angle with their crest; the arch of the upper jaw was widened more than an incb; the hard palate had been entirely absorbed, and the alveolar ridge bent ontwards. The channel of the right nostril was nearly obliterated by the tumour, but 
there was little or no bulging into either orbit. The pulse was quick and weak, the temperature normal, and the urine of a healthy standard. The boy was placed for a time on a liberal diet to prepare him for operation.

On May 28th the following operation was performed:The patient having been prepared as usual, and being fully under the influence of chloroform, laryngotomy was first performed to allow of respiration after the plugging of the fauces. At the first incision the middle thyroid vein was divided, but was at once secured, and the tracheal tube was readily introduced. The pharynx and back of the mouth were then carefully plugged with soft, clean sponges, to prevent blood finding its way into the trachea or down the esophagus. Breathing and the inhalation of chloroform was carried on through the tracheal tube. Skin flaps were then made, as in Sir William Fergusson's operation, and the nasal process of the superior maxilla was divided with the bone forceps. The anterior wall of the antrum was next removed, and it was then found that the tumour was of much deeper origin than had previously appeared. The tumour sprang, not from the superior maxilla, but from the body and the pterygoid processes of the sphenoid bone, the back of the pharynx, and the margin of the foramen magnum. The base of the tumour was large. At the furthest point to which a ligature could be pushed it measured two inches in diameter. A stout whipcord ligature was passed round the tumour, and it was cut off ; the bleeding of the surrounding parts, which at the time appeared to be profuse, was arrested by swabs of cottonwool, steeped in a strong solution of the perchloride of iron. Probably the total loss of blood did not amount to one pint, but the patient was much exhausted, his respiration was feeble, and his pulse imperceptible at the wrist. The wound was therefore closed with wire sutures and hare-lip pins, the sponges were withdrawn from the throat, and every effort was made to rally the patient. After a time these efforts were partially successful, and a certain degree of reaction took place. The pulse returned, the temperature rose, some dark fluid was vomited, the patient was fully conscious, and swallowed fairly; but he continued in a state of semi-collapse, and gradually sank until he died at 6 P.M.

Post-mortem examination. - The tumour was found to have the attachments described. A separate process of the tumour attached to the edges of the spheno-maxillary fissure grewin to the spheno-maxillary fossa. The mucous membrane of the pharynx and cesophagus was discovered and peeled off easily as far as the cardiac end of the stomach. The stomach contained half a pint of fluid coloured black by tannate of iron; a patch of its mucous membrane near the cardiac opening was deeply congested and passing into gangrene. The larynx and trachea were normal.

Remarks by Prof. RATTON.-The tumour was attached not only to every bony prominence in the nares and pharynx, but it sprang chiefly from the body of the sphenoid and back of the pharynx. Most of its attachments were broken down with the fingers, but in so doing brisk bæmorrhage was caused, although the tumour was a fibroid. It was, however, in a sense gratifying to notice how quietly and unconsciously the patient lay throughout the operation. There was no shifting about, gulping, gasping, or disturbance of any kind. After the operation the wound was plugged with lint soaked with perchloride of iron, and the sponges were withdrawn. This was a mistake, because the secretions loaded with strong perchloride of iron gathered at the back of the pharynx, the patient swallowed them, and, as the post-mortem showed, the cesophagus was thus damaged from end to end. Perchloride of iron should not have been used. It would have been better to have applied the actual cautery, but the perchloride seemed milder at the moment, and it was effectual. The sponges need not have been withdrawn until there was a call for food. Again, it would perhaps have been well to have covered the sponges with gutta-percha tissue to keep them from swelling with blood, styptics, \&c. They were a little difficult to withdraw. The tracheotomy tube was left in for six hours.

St. Thomas's Hospital Medical School. - The Entrance Science Scholarships given this year have been awarded as follows, $\nabla i z$. :- The scholarship of $\& 60$ to $\mathrm{Mr}$ Wansborough Jones, B.A. Oxon., and B.Se. London; and that of $\& 40$ to Mr. A. E. Wells, of the University of London.

\section{Am Medital Sorteties.}

\author{
CLINICAL SOCIETY OF LONDON.
}

Hysterical Anoesthesia._Injury to Spinal Cord.-Cerebro-Spinal Lateral Sclerosis.

THE ordinary meeting of this Society was held on the 26th October, the chair being occupied by Mr. Bryant. The subjects discussed were all examples of nervous diseases, the most important being a remarkable case of hysterical anæsthesia in a boy, related by Dr. Henry Thompson. In this case the results obtained abroad by the application of metals (here gold) in restoring sensibility and vascularity to the insensitive parts, were confirmed on many occasions and under varying conditions. Mr. Brudenell Carter, in the course of the discussion, pointed out that the phenomena presented by hysterical subjects should be received with the greatest reserve, and protested against their being accepted as facts worthy of serious investigation. Other speakers, however, as Drs. Althaus, Broadbent, Glover, and Barlow, did not share these views.

Dr. CAYLEY read notes of a "Case of Hysteria, with Contracture of the Lower Limbs, Anæsthesia, and Ischæmia, in a Boy," communicated by Dr. Henry Thompson. The patient, fourteen years of age, son of a French father and English mother, was admitted into the Middlesex Hospital on May 10th, 1877. He had always been delicate, but had no definite illness till two months before admission, when he began to lose flesh, became low-spirited, and complained of vertical headache. He had occasional paroxysms of laughing and crying, accompanied by a hoarse barking cough and globus. For a month he had been unable to walk owing to paresis, rigidity, and distortion of his lower limbs. On admission his pulse, temperature, and respiration were normal, and remained nearly so throughout the case. His voice was almost inaudible, but was strengthened by weak faradaism. The legs were firmly flexed upon the thighs, and the feet extended as in talipes equinus. The genital organs were ill-developed. Anæsthesia and ischæmia were prominent symptoms from first to last, and on May 18th experiments were made to define these conditions, with the following results:-At the time of observation be was very impassive, but the senses of sight and hearing were normally acute. There was complete cutaneous and deep anæsthesia, to ordinary and to painful impressions, on his cheeks, forearms, and in fact over the whole body; punctures were made down to the bone, and none of them were followed by any bleeding. Faradaism being applied to the right forearm, the seats of puncture began to bleed, but the anæsthesia persisted. Gold coins were then applied, and it was noticed that after their application for ten minutes, sensation returned over these regions, and punctures produced bleeding, the range of sensibility gradually diminishing in every direction from the area over which the coin was placed. These experiments were repeated on the 19th, 21st, 29th, and on several subsequent occasions, with invariably the same result. Like observations were made with other metals, insulated and non-insulated, and with wood, with the boy's attention drawn to it, or, on the other hand, wholly without his knowledge, but only with the gold could the above results be obtained. On one or two occasions the gold failed, but never when it had been applied as long as ten minutes. Once a puncture made into the leg, whon he was asleep, produced pain and free bleeding. In about a month after his admission, he had so far recovered the use of his limbs as to be able to walk about with the aid of a stick. It was not until fully three months after his admission that the anæsthesia and iscbæmia passed away, and he left the hospital on Aug. 25th, able to walk fairly well, and with his sensibility and capacity for bleeding everywhere normal. With the exception of being treated for two severe attacks of bronchitis, shower-baths, faradaism, valerian, cod-liver oil, and iron, were the only remedies adopted. Dr. Thompson pointed out that the case was one 